\title{
La mujer en las formas de relación entre núcleos y territorios de la Iberia protohistórica. I. Testimonios literarios
}

\author{
Eduardo Sanchez Moreno *
}

RESUMEN SUMMARY

\begin{abstract}
Las siguientes páginas prestan atención al papel desempeñado por la mujer en la formulación de relaciones de distinto sello entre habitantes de la Peninsula lbérica durante los últimos siglos de la Edad del Hierro. A través de una serie de ejemplos comentados,

extraidos exclusivamente del registro literario y ceñidos en principio al ámbito meseteño, se revisa la figura femenina como elemento de interacción social. Entre los diferentes comportamientos recogidos cabe destacar por una parte la práctica exogámica y, dentro de un segundo bloque más heterogéneo, la explotación de la mujer como instrumento en la apertura de contactos intercomunitarios. El talante de los mismos (relaciones diplomáticas, comerciales, presión militar o cultural, etc.), está en consonancia con el uso que en cada caso se haga del género femenino.
\end{abstract}

The following pages deal with the role played by the women into different relationships developed among the Iberian Peninsula peoples during the last centuries of the Iron Age. Through the commentary of some examples coming from the written sources and relating to the Meseta territory, mainly, the feminine figure is revised as an element of social interaction. One of the most important forms is exogamy. and. secondly, the woman exploitation as an instrument in the opening of intercommunity contacts. The nautre of these contacts (diplomatic, trading. military or cultural relations) depends on the services made by women in each case.

* Departamento de Historia Antigua. Universidad Autónoma de Macirid. 


\section{A) MATRIMONIOS MIXTOS: DE RELACIONES DE PARENTESCO A ALIANZAS POLITICAS}

El matrimonio representa una estrategia social de aplicación antiquísima habida cuenta que la mujer es garantía, vínculo carnal y vivo que consolida un acuerdo efectuado por motivos específicos, amén de instrumento indispensable de una descendencia esperada. Desde bastantes años atrás, los estudios antropológicos llevan contemplando la exogamia como uno de los fenómenos transculturales más trascendentes, hasta el punto de constituir para muchos la piedra de toque en la articulación del parentesco. El antropólogo francés $C$. Lévi-Strauss fue de los primeros en reglamentar los sistemas matrimoniales como mecanismos de alianza basados en el concepto de intercambio entre familias '. Para la etnología clásica, el sistema de parentesco se define como regla positiva de alianza a partir de la donación de mujeres entre grupos extraños, estableciéndose entre los mismos relaciones de consanguinidad. Según este modelo, el principio que genera tal funcionamiento es la prohibición universal del incesto a favor de la exogamia (intercambio de mujeres), entendida como contrapartida positiva que supera un comportamiento natural por uno cultural y reglamentado. La obligación de practicar la exogamia fuerza a las sociedades a organizarse en grupos de parentesco y a establecer relaciones de intercambio con otros grupos?.

LfVi-Sirauss. C.. Les structures elémentaires de la parenté. París, 1949. Ya antes, E. B. TYLOP ("On a method of investigating the development of institutions: applied to laws of marriage and descent". Journal of the Royal Anthropological Institute. XVIII. 1888. pags. 245-272) se habia referido al enlace de comunidades primitivas en función del trueque de mujeres como alternativa al vivir guerreando: “...either marrying out or being killed out" (pág. 267).

Una sintesis sobre la evolución de este pensamiento en ZONABEND. F.. “De la familia. Una visión etnológica del parentesco y la familia”, en Burgutere. A et alii (Dir.). Historia de la familia. 1. Mundos lejanos mundos antiguos. Madrid. 1988, espc págs. 34-48. Tocante al arranque de la exogamia y su evolución. en un manual ya clásico R. Fox (Sistemas de parentesco y matrimonio. Madrid, 1985. $4^{\mathrm{a}}$ edición. págs. 161-191) encuentra la respuesta al origen en la extensión de ta idea de reciprocidad más alla de los limites de la banda con el fin de contar con alguna relación cooperativa entre las mismas. De la exogamia más primitiva. la del trueque simultáneo. se pasó al denominado intercambio de mujeres de forma directa diferida en generaciones sucesivas y alternativamente, relacionable con el valor del regalo y el sentido de prestación o deuda que el don crea en quien lo recibe y hacia quien lo otorga (Mauss. M. "Essai sur le don. Forme et raison de lechánge dans les sociétés archaïques". L Année Sociologique. I. 1925. págs. 30-186: edición en castellano "Ensayo sobre los dones. Razón y forma del cambio en las sociedades primitivas". en Sociologia y Antropologia. Madrid, 1971. págs. 155-263). La deuda pendiente por el regalo (la mujer, traducida en unión exogámica) se saldara en un futuro con la entrega. en sentido inverso, de otra mujer. la que la comunidad en débito ofrece cono regalo respuesta (reciprocidad) y. sobre todo. como fórmula de mantenimiento de la alianza y amistad entre ambas sociedades, cada vez más sólidamente emparentadas. Todo ello consolida lo que Fox denomina la alianza perpetua entre dos grupos: "Detengámonos ante los sistemas elementales de intercambio. ¿qué misión cumplen? La 
A pesar de ciertas críticas y de corregirse en los últimos años el enfoque tradicional de la teoría del parentesco ${ }^{3}$, se sigue considerando el matrimonio fuera del grupo de filiación como forma principal de contacto, intercambio y diplomacia intercomunitarias ${ }^{4}$. La traducción final en muchas sociedades primitivas fue el intercambio sistemático de mujeres, que son quienes suelen viajar de su grupo endógeno para integrarse en otro que hasta ese momento les es ajeno.

Pisando un terreno más concreto, en las fuentes literarias se puede otear la realidad de este hecho en contados episodios de la Iberia prerro. mana a pesar de la escasez, el carácter tardío y el condicionamiento de los textos clásicos. El signo de estas prácticas, no obstante, es ya marcadamente político (alianzas) y no tanto antropológico, ya que los testimonios proceden sustancialmente de fuentes de conquista de contenido políticomilitar, y no son relatos etnográficos carentes de prejuicios.

La información sobre los matrimonios indígenas es muy superficial. El dato más directo lo transmite Estrabón (III, 3, 7) al enjuiciar que los cántabros se casan a la manera griega. No queda claro el sentido de la comparación del geógrafo: si se está refiriendo al rito nupcial o más bien al do-

contestación es: intercambio y alianza. Cualquiera que sean las unidades implicadas - familias. bandas. linajes, clanes. mitades. tribus... - . unas y otras entran en relaciones de intercambio y constituyen alianzas. Los sistemas elementales de alianza marital perpetúan las alianzas a través de los tiempos: puesto que dimos a usted mujeres. continuamos dándoselas: unáa vez que hemos tomado de usted mujeres. seguimos tomándolas a perpetuidad" (Fox. R. op. cit., 1985. pág. 202).

Por ejemplo. Goovy. E. "Marriage, prestations, inheritance and descent in pre-industrial societies". Journal or Comparative Family Studies, vol.l. 1. 1970: Rubin. G.. "The traffic in women: notes on the political economy of sex". en REITER. R., (ed.). Toward an Anthropological of women. Nueva York-Londres. 1975 (reeditado en castellano. en LAMAS. M.. comp. El género. la construcción cultural de la diferencia sexual, México. 1996. págs. 35-96): Collaro. C. "Echangés. échangistes. structures dominées et dominante d'échange matrimonial: le cas Guidar. Culture. 50 (1). 1980. pags. 3-12: quienes. sin negar del todo la realidad del matrimonio como instrumento de alianza dentro de la cual la mujer circula como mercancia. rechazan que el intercambio sea la base del matrimonio.

* Para Service la reciprocidad de matrimonios es la opcion más temprana. esencial y también más segura de crear un vinculo. y. junto con el trueque de bienes, constituye la relación exterior principal entre sociedades igualitarias: "(...) alianza. básica. obvia. planificada. politica. mente proyectada, mediante los intercambios de contrayentes. Por supuesto, el matrimonio es el medio en que se originan los parientes por afinidad y. en la generación siguiente. los nuevos parientes consanguineos. Forma de extender fuera de los limites el dominio doméstico (...) "(SERVICE. E. R., Los origenes del Estado y de la civilizacion. El proceso de la evolución cultural. Madrid. 1984. 2" edición 1984, págs. 80-82). En linea similar. Shalins. M.. Stone Age Economies. Nueva York. 1972. pags. 222-223 (edición en castellano: Madrid. 1977): para las comunidades domésticas y desde el punto de vista del materialismo histórico. Melliassoux. C.. Mujeres,

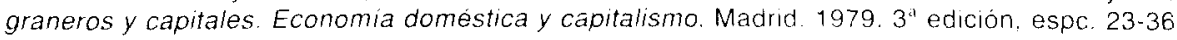
y $93-100$ 
minio de la monogamia en la lberia prerromana ${ }^{5}$. De algunas fuentes subyace la idea de que las bodas en las comunidades celtibéricas se llevaban a cabo en días precisos ${ }^{6}$, lo cual indicaria un carácter ceremonial y consolidado de la institución del matrimonio que acaso podría hacerse extensivo, aprovechando la reunión de varios pueblos, a uniones mixtas en fiestas programadas, con sentido incluso religioso o político. Pero no hay noticias directas que lo confirmen.

Sin embargo parece lógico pensar que en la antigüedad hispana el matrimonio es un acto cultural de capital importancia, además de serlo desde el punto de vista jurídico y familiar. Aunque sea un acontecimiento privado, permite la asistencia colectiva cuando quien protagoniza el enlace es un personaje importante y forma parte de la élite aristocrática. El caso paradigmático es la ya aludida boda de Viriato con la hija del rico Astolpas, relatada por Diodoro (XXXIII, 7, 1-7). Con ocasión de estas nupcias se concentra mucha gente, probablemente también asisten invitados extranjeros, se organizan banquetes y otras fiestas de mérito, se exhiben las alhajas del potentado lusitano y suponemos que también se intercambiarían regalos. Si el matrimonio es un enlace mixto de carácter

Asi to cree R. LuCAS ("La mujer: simbolo de fecundidad en la España prerromana". en GARRiDO. E.. ed. La mujer en el mundo antiguo. Madrid. 1986, 2* edic. 1995. pág. 351): "al igualar el matrimonio indigena al griego. presuponiendo una serie de formalismos y rituales de despedida y entrega. acompañados de regalos y festejos. interrumpidos en las bodas de Viriato por las diferencias entre suegro y yerno, que despreciando las normas de cortesia (ni se lavó ni se sento a la mesa), tras sacrificar a los dioses, montó a la novia en un caballo y partió hacia la montaña (Diodoro, XXXIII, 7, 1)". Un análisis sobre el simbolismo del matrimonio por rapto, desde una perspectiva etnogrática. en Pitu-RIvers. J., "Matrimonio por rapto". en Pefistiany. J.G. (Ed.), Dote y matrimonio en los paises mediterráneos. Madrid, 1987. págs. 345-367.

La opinión mayoritaria es hablar de la generalización del hábito monógamo en la lberia indigena. Tenues indicios arqueologicos (algunas tumbas dobles) parecen indicarlo. Sin embargo autores como Caro Baroja. siguiendo el relato moralizante puesto en boca de Viriato por Diodoro (XXXIII. 7. 5) acerca de un hombre casado con dos mujeres, una joven que le quita las canas para simular su mayor edad y una mayor que elimina los cabellos de color del marido para adecuarle a su ancianidad, defienden la existencia de la poligamia en la Lusitania antigua (CARO BAROJA, J., Los pueblos de España. 1-1l. Barcelona, 1976. págs. 187-188).

Sexto Aurelio Victor (49) afirma que los matrimonios celtibéricos se verificaban en un mismo dia. Algo parecido en Salustio (De vir. ill., 59): eo die Numantini forte solemni nuptum filias locabant...: a proposito de los pretendientes de una bella celtibera, que para desposar a la joven han de traer la diestra de un enemigo por mandato del padre de la muchacha. Por otra parte. también Salustio (Hist.. II, 91) afirma que las mujeres no eran llevadas al matrimonio por sus padres. sino que ellas mismas escogian a los que más se distinguian en la guerra.

Sobre la mujer celtibérica en general pero con especial atención al coraje que muestran a ojos de los historiadores greco-latinos: SOPENA. G. Etica y ritual. Aproximación al estudio de la religiosidad de los pueblos celtibéricos. Zaragoza. 1995, págs. 50-69. Acerca de los sistemas de genero entre los pueblos prerromanos: GARrido. E., «Parte II. La construcción del patriarcado en la España antigua". en Garkidoo. E.. (ed.). Historia de las mujeres en España. Madrid. 1997, espc. capitulo 4, págs. 81-97 
político, como en parte se desprende de la misma boda de Viriato, el acto se puede repetir a escala menor, en la idea de que al tiempo que se casa el jefe, se realiza la unión de sus guerreros o seguidores más cercanos con damas, parientes o sirvientas de la novia principal, reforzando de forma plural el principio político que un acontecimiento de esta altura encubre como sanción simbólica. Esto es lo que ocurre, por ejemplo, en los esponsales de Alejandro Magno con princesas iranias, que se vieron prolongados en el enlace de ochenta de sus soldados con hijas de nobles indigenas. Lógicamente estos matrimonios de gran categoria debieron ser minoritarios y selectivos en el conjunto de las comunidades prerromanas, pero hallamos eco del despliegue de politicas matrimoniales en las fuentes.

Tanto Asdrúbal Barca (Diodoro, XXV, 12), como su cuñado Aníbal (Livio, XXIV, 41,7) se habían unido a mujeres iberas, sin duda de alta alcurnia, como Imilce, natural de Cástulo, casada con Anibal (Silio Itálico, III, 97). Se trata de una maniobra púnica de carácter político que tiene como meta la captación de partidarios indigenas, sellando acuerdos que se materializarian con actos ceremoniales tan vinculantes como el entroncamiento con la familia bárquida. De hecho, Diodoro señala que una vez contraido matrimonio con la hija de un rey ibero, Asdrúbal es proclamado por muchos indigenas general con plenos poderes, un titulo que encaja perfectamente con costumbres sociales del tipo de la devotio y fides ibéricas. Sólo estos dos testimonios de matrimonios mixtos aparecen revelados con nombres propios en los textos clásicos. pero no se nos antoja aventurado pensar que enlaces políticos de este tipo debieron ser relativamente frecuentes ${ }^{\text {? }}$, no sólo entre púnicos e in-

Opiniones al respecto: "los casamientos mixtos entre colonizadores e indigenas no debieron estar prohibidos, y entre grupos étnicos y estratos más o menos afines. La mujer, o mejor dicho la politica matrimonial tomentaba la cohesión entre distintos segmentos sociales" (LUCAS, R. art. cit., 1986, pág. 351\}. "La sociedad fue exógama y a tal respecto se constatan las uniones para realizar pactos y matrimonios de carácter politico donde las mujeres se utilizaron para consolidar las relaciones diplomáticas y que tuvieron por objeto las alianzas matrimoniales con las princesas iberas" (RuANO, E., "El amor y el matrimonio entre los iberos". Espacio. Tiempo y Forma. Serie II. Historia Antigua. 7. 1995, pág. 162); en linea parecida se pronuncia C. MARtinez Lopez ("Las mujeres en la conquista y romanización de la Hispania meridional”. Florentia lliberritana, 1, 1990. págs. 247-248), destacando el comercio social en el que las mujeres ibéricas actuan como bienes preciosos con funcionalidad político-parental; esta autora pone enfasis en el cambio que la nuevas formas sociates romanas imponen interrumpiendo la tradición de alianzas indigenas. Con una postura reivindicatoria de la mujer. E. Garrido denuncia que "mientras ellas eran capaces de transmitir privilegios, al mismo tiempo la reciprocidad de beneficios no se realizaba en sus personas sino que repercutía en la comunidad a la que pertenecian o bien beneficiaba a la autoridad masculina (paternal) que habia sido el verdadero actor de la acción mientras que ellas eran solo agentes pacientes en provecho del poder masculino" (GARRIDO. E. op. cit., 1997. pág. 82). 
dígenas ${ }^{8}$, o entre caudillos locales de territorios cercanos (caso de los ilergetas Mandonio e Indíbil, cuñados entre sí, ya que la mujer de Mandonio era hermana del segundo; Polibio, $X, 18,3)$, sino también entre comunidades peninsulares diferentes, tanto del ámbito cultural iberico como del indoeuropeo ${ }^{9}$. De ello tenemos un refiejo abstracto en Diodoro $(\mathrm{V}, 33)$, cuando a propósito de la pueril explicación que asigna a! concepto celtiberos nos da a saber la trascendencia de la exogamia, haciendo uso de un dato seguramente histórico dentro de un argumento de dudosa etiologia: "Estos pueblos, iberos y celtas, en otro tiempo habian peleado entre sí por causa del territorio; pero hecha la paz habitaron en común la misma tierra: luego, por medio de matrimonios mixtos, se estableció afinidad entre ellos y por esto recibieron un nombre común". En el trasfondo de estas relaciones diplomáticas entre esferas más o menos distantes, por ejemplo la meseta y el sureste ibérico, hay que enjuiciar las motivaciones económico-comerciales (concretadas en la necesidad de intercambiar productos como ganados, cereales, sal o tráfico humano, además de minerales) y las de sello político (alianzas militares sean éstas eventuales o renovaciones, etc.).

Consideramos, pues, que las uniones matrimoniales entre grupos ajenos tuvieron una importancia en los géneros de vida de la Protohistoria peninsular mucho mayor de la tradicionalmente pensada, tanto en lo que

8 En escala jerárquica paralela y descendiente: por ejemplo, legados al servicio del cartaginés con damas principales de ciudades o territorios de interés estratégico en la politica bárquida. Algo asi hemos sugerido no sin cierto riesgo para el episodio de la toma de Helmantica por parte de Anibal en el 220 a.C., en el que las valerosas mujeres de la ciudad consiguen sacar a escondidas las armas y entregárselas a los hombres (Plutarco. Virt. Mul., 248: Polieno. VIl, 48) (sobre este acontecimiento, vide el veterano trabajo de $M^{\star}$.C. FERnANDEz ChICARRO, "Valor de las mujeres salmantinas en las campañas contra Hannibal». Helmantica. 17, 1954, págs. 257-264). Tras el auxilio de las mujeres. la huida de los indigenas y la persecucion de Anibal, sabemos que hay una súplica final de perdón por parte de los salmantinos y una respuesta benevolente del cartaginés restituyéndoles su situación y posesiones...; ¿no podrian estar disfrazando estos hechos relatados en clave moralista por las fuentes griegas un acto diplomático mas o menos forzado entre Anibal y los habitantes de la ciudad del Tormes. sellado (o mejor garantizado) mediante prácticas como la toma de rehenes, la concesión de privilegios o, yendo más lejos y para el caso que nos compete, la realización de matrimonios mixtos entre representantes bárquidas y mujeres nobles locales? (Sanchez Moreno. E. Meseta occidental e lberia exterior. Contacto cultural y relaciones comerciales en época prerromana, Tesis doctoral inédita. Universidad Autónoma de Madrid. 1997, págs. 339-343).

Entre los galos sabemos que por ejemplo Dumnorix, jefe eduo, enlaza a miembros de su familia con gentes de los bituriges y con otros principes extranjeros, caso de la familia de Orgetorix. jefe helvecio, pues él mismo habia desposado a una hija de este (CESAR, B.G. I. 3, 9 y 18). A veces son alianzas a larga distancia, como los matrimonios de Ariovisto, rey germano del este de la Galia, primero con una princesa sueva y en segundas nupcias con una hermana de Voción, rey del Noricum, en la actual Austría, a más de $600 \mathrm{~km}$. de la patria de Ariovisto (CESAR. B.G.. I. 52). una región destacada por su tradición comercial y por la riqueza en hierro. 
atañe a las relaciones entre indigenas y colonizadores ${ }^{10} \mathrm{como}$ a las establecidas entre grupos autóctonos. En la valoración completa de este fenómeno puede contribuir la arqueología, en concreto la lectura de ciertos objetos exóticos en determinados contextos funerarios que ahora no toca estudiar ${ }^{11}$. Además no hay que ver la exogamia exclusivamente en un sentido principesco, excepcional y entre centros de poder muy distantes (caso paradigmático de la política matrimonial de los Bárquidas, enlaces dinásticos merecedores de la observación de los clásicos). Debió de funcionar también en niveles sociales menos privilegiados, constituyendo una práctica en uso por un mayor número de individuos, conectando socieda-

observa la práctica de matrimonios mixtos y su trascendencia cultural. en términos de aculturación de distinta dirección, es la colonización griega. Las fuentes clásicas no precisan nada para el caso de Iberia. pero otrecen valosos retazos para otros lugares. caso del matrimonio entre Protis. uno de los lideres foceos en la tundacion de Massalia. y Gyptis. hija del indigena Nannos, rey segóbrigo (Justino. XLVIII. 3. 4). La importancia de los matrimonios mixtos como factor de interculturacion en el ámbito de la colonizacion gan compernolle (uFemmes especial en la Magna Grecia. es objeto de atención por parte de R. Van Comazione nelle societá antiindigénes et colonisateurs", en Forme di contatto e processi MONEDERo ("Consideraciones acerca ché. Pisa-Roma. 1983, págs. 1033-1049). A. J. Dominguez Mediterraneo occidental», en GarRido. E.. ed., La

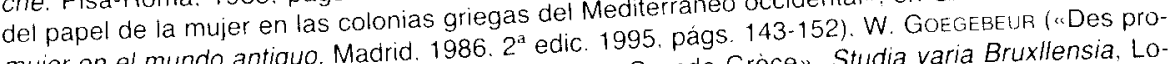
Cintermarriage en Grande Grèce”. Studia varia Bruxllensia, Loblemes liés a l'interculturation ef Iintermarrag ("Mixed marriages at the frontiers of the Early Greek vaina. 1987. págs. 55-62) y J. N. COLDSTREAM (4. 1993. págs 89-107). Este asunto ha sido enfocado World". Oxford Journal of Archaeology. 12. 1. 19.ipacion de las mujeres griegas en el fenomeno cocon frecuencia dentro del debate sobre seguida es asumir que la aventura colonial es una empresa protagonizada casi en exclusiva por varones (ROUGE. J.. "La colonisation grecque et les femmes". Cahiers d Histoire. 15, 1970. pags. 307-317; R. VAN COMPERNOLLE. art cit.. 1983; A. J. DOMINGUEZ MONEDERO, art. cit. 1986). lo cual acentúa la necesidad de mezclarse con mujeres locales y favorecer el inicio de los procesos de contacto cultural. Sin embargo otros análisis, como el de A. H. GRAHAM ("Religion. women and Greek colonization", en Atti Centro Ricerche e Documentazione sull Antichita Classica. 1990-91, Roma. págs. 293-314), defienden la presencia de -e insustituible-en mujeres en la empresa colonial desde el principio. Como elemento de los metrópoli; al margen de la realidad que supone el establecimiento de enlaces exogámicos entre varones griegos y nativas. Nos referimos a la interpretación de piezas a muerte llegadas ahi por enlace matrimonial téminas distinguidas y extranjeras en el lugar de su muerte, ltorques, diadernas, fibulas, broches con jefes locales. Se trata generalmente de joyas singulares (torquestizante (véase al respecto el de cinturón...) en la orfebrería del Bronce Final y del Periodida: orfebreria, herencia y agricultura interesante ensayo de M.L. RuIz-GaLver. "SPAL. Revista de Prehistoria y Arqueologia de la en la Protohistoria de la Peninsula Iberis-251). Nosotros mismos hemos avanzado alg'ına proUniversidad de Sevilla. 1, 1992. págs. 219 necropolis vetona de la Segunda Edad del Hierro, sin supuesta en sentido parecido para una nofENO, E.. "Mecanismos de contacto cultural al occidente perar el nivel de hipotesis (SANCHEZ Mon. IV Simposio sobre los Celtiberos. Economía. Daroca. de la Celtiberia". en BuriLLO. F.. Coor. " un trabajo mas profundo ( La mujer en las formas de re1997 ; en prensa). y estamosicica. II. Testimonios arqueológicos"). complemento de éste dedicado a la información literaria 
des en ocasiones bien cercanas y homogéneas de forma renovada y tradicional, tal como refrenda la dinámica etnográfica.

\section{B) INSTRUMENTALIZACIÓN DE LA FIGURA FEMENINA. OTROS USOS DE LA MUJER EN EL CONTACTO INTERGRUPAL}

En efecto, la mujer representa un notable papel en la diplomacia de indígenas y conquistadores ${ }^{12} \mathrm{y}$ en las relaciones formuladas entre entidades locales al proyectarse, manipulada de diferente forma, en conexiones intercomunitarias. Es utilizada como argumento (político, social, comercial, sexual, de prestigio...) que pone en contacto a gentes diversas. Recopilamos para terminar algunos de los papeles desempeñados por determinadas féminas en este sentido que aparecen aludidos en los textos. El contexto de estas noticias está teñido de romanidad por lo tardío de las fuentes, pero lo universal de las categorias femeninas recogidas permite extrapolarlas con ciertos límites a los mecanismos de contacto prerromanos:

\section{Mujer como instrumento de presión: rehén}

La captura de una mujer principal en la estructura dirigente del enemigo (esposa, prometida o hija de un adversario, pongamos por caso) actúa como medida de coacción política para forzar negociaciones, alianzas y concesiones ${ }^{13}$. Son varios los ejemplos de mujeres tenidas por prisioneras políticas en tiempos de la conquista:

a) En el 209 a.C. tras la toma de Cartago Nova, Escipión devuelve a Alucio, jefe celtíbero, a su prometida y gana, así, su adhesión, nada despreciable pues el celtibero ofrece a Escipión 1.400 équites de su séquito para que formen parte del ejército romano (Livio, XXVI, 50; Dion Cassio, Fr. LVII, 42; Frontino, II, 11, 5; Valerio Máximo, IV, 3, 1; Polieno, VIII, 16, 6; Aulio Gelio, N.A., VII, 8, 3). Por cierto, la joven parece ser una cautiva de los cartagineses natural de esa región murciana, su compromiso matri-

\footnotetext{
12 Martinez Lopez, C., "Las mujeres de la Península lbérica durante la conquista cartaginesa y romana", en GARRIDO, E., ed., La mujer en el mundo antiguo, Madrid, 1986, (2a edic. 1995), espc. págs, 392-394.

13 BlazQuez, J.M.M., "Las alianzas en la Península lbérica y su repercusión en la progresiva conquista romana", Revue Internationale du Droit d'Antiquité, 14, 1967, pág. 209 (reeditado con puesta al día en BLAzQUEZ, J.M ... España Romana, Madrid, 1996, págs. 95-117); MARTINEZ LOPEZ, C., art. cit., 1986, págs. 393-394. Véase tambièn, MANGAS, J.. "El papel de la diplomacia romana en la conquista de la Peninsula lbérica (226-19 a.C.)". Hispania, 116, 1970, pags. 485-513
} 
monial con un jefe celtibérico revela la alianza entre dos comunidades alejadas, rubricada con un enlace exogámico. Esta interpretación nos parece más adecuada que la mantenida por Blázquez, quien considera que la presencia en el sureste de este príncipe meseteño es una prueba de la expansión celtibérica ${ }^{14}$, un temá hoy sometido a revisión.

b) El mismo Escipión entrega a Edecón, reyezuelo de los edetanos, a su mujer e hijos; y a petición de éste, Escipión firma una alianza que motivó que otros pueblos abrazaran la causa romana (Polibio, $X, 34$ ).

c) El mismo general es el encargado de devolver a Indíbil a su mujer $e$ hijas, cautivas hasta entonces (las fuentes se explayan en el extremo decoro con que Escipión trata a las prisioneras cartaginesas, iberas y celtíberas; Polibio, X, 18, 3; X, 19, 3; Floro, 1, 22, 32; Cornelio Nepote, De vir. ill, 49).

d) Tiberio Sempronio Graco toma como rehenes en 179 a.C. a los hijos e hija de Thurro, importante jefe indígena, en la ciudad de Alce, que son devueltos a su padre consiguiendo Graco con ello el apoyo del caudillo íbero (Livio, XL, 49).

e) Entre grupos indígenas, Viriato restituye a los segovienses, aliados de Roma, a sus hijos y esposas hacia el 146 a.C. (Pseudo Frontino, III, 10, 6).

f) En contexto menos preciso, los baleáricos son capaces de ofrecer por el rescate de sus mujeres tres o cuatro hombres (Diodoro, V, 17, 2-3); según Lucas ${ }^{15}$ por la escasez de mujeres en la isla que explica el comentario del historiador sículo sobre los recién casados que comparten la mujer en el lecho con familiares y amigos, por orden de edad.

\section{Mujer como bien de recompensa: regalo}

La mujer puede ser también un don de obsequio para quien se distingue en un hecho político o para redondear un acto diplomático. Con tal fin, Escipión, conquistada Cartago Nova, recibe una doncella como dádiva; dando ejemplo de gallardía a sus soldados, el romano respeta a la joven con un gesto que no ha pasado desapercibido en las fuentes (Polibio, $X$, 19, 3; Livio, XXVI, 50; Dión Casio, LVII, 42; Frontino, II, 11, 5; Floro, I, 22, 38; Cornelio Nepote, De Vir. II., 49; Valerio Máximo, IV, 3, 1: Aulio Gelio,

14 Blazquez, J. M $M^{a}$., "La expansión celtibera en Carpetania. Bética, Levante y sus causas (ss.ll-li a.C.)", Celticum. 3. 1962, págs. 419-420,

LUCAS. R., art. cit., 1986, pág. 351 
N.A., VII, 8, 3; Polieno, VIII, 16, 6). En ocasiones la entrega de mujeres puede ser colectiva y reciproca entre dos grupos: con ello se fortalecen las líneas de parentesco entre ambas sociedades y, en esencia, se consolida el acuerdo político que motiva la alianza dinástica, tal como ya ha sido apuntado ${ }^{16}$.

\section{Mujer como bien comercial: mercancia}

Por cuestiones diferentes (carestía, deseo sexual, prestigio social, razones económicas, culturales o religiosas...) la mujer es un objeto apetecido, por tanto un elemento de intercambio que se demanda incluso a los mercaderes. Al respecto, nos dice el Pseudo Aristóteles (Relatos maraviIlosos, 85): "En las islas Gimnesias, el aceite surge del terebinto y sus habitantes son tan dados a las mujeres que ofrecen cuatro o cinco vacas por una sola mujer a los mercaderes. Cuando se les paga, aparentemente sólo compran mujeres. No se les permite tener oro ni artículos de plata para impedir que introduzcan oro ya que Heracles hizo una expedición contra lberia por sus riquezas" ${ }^{17}$.

Lo anecdótico de esta historia no quita valor a la inclusión de la mujer en el horizonte de los intercambios culturales, económicos y políticos entre sociedades.

16. Fox, R. op. cit., 1985, págs. 161-191

Traducción Gomez ESpelosin, F.J. el alii. La imagen de Hispania en la Antigüedad Clásica. Madrid, 1995, pág, 191 